\title{
Relationship of Training in Acupuncture to Physician Burnout
}

\author{
Paul F. Crawford, III, MD, Jedda Rupert, MD, Jeremy T. Jackson, BA, \\ Stevan Walkowski, DO, and Christy J. W. Ledford, PhD
}

Background: Physician burnout is an ongoing problem that affects both physician wellbeing and patient care. Burnout is characterized by emotional exhaustion and depersonalization. Studies have explored ways to prevent and alleviate burnout. Receiving training in acupuncture may reduce physician burnout.

Objective: The purpose of this study is to determine if acupuncture training is associated with less patient depersonalization and less emotional exhaustion among physicians.

Methods: These self-reported data were collected from a cross-sectional survey of family physicians at the Uniformed Services Academy of Family Physicians 2017 conference. Physicians answered questions regarding their level of acupuncture training as well as questions about burnout (depersonalization and emotional exhaustion).

Results: The overall response rate was $66 \%(325 / 492)$. Of these, 233 cases provided complete datasets. In a model controlling for years' practice and clinical pace, acupuncture training was significantly associated with decreased depersonalization, $F(1,194)=5.82, P<.05$.

Conclusion: Study data show an association between decreased physician depersonalization and acupuncture training, suggesting acupuncture training may be a helpful strategy to reduce family physicians' depersonalization of patients. (J Am Board Fam Med 2019;32:259-263.)

Keywords: Acupuncture Therapy, Depersonalization, Family Physicians, Integrative Medicine, Professional Burnout, Self Report

Physician burnout has become the focus of considerable discussion and research in recent years. Through their work, physicians' emotional re-

This article was externally peer reviewed.

Submitted 19 July 2018; revised 29 November 2018; accepted 4 December 2018.

From the Department of Family Medicine, Uniformed Services University of the Health Services, Bethesda, MD (PFC, CJWL); Nellis Family Medicine Residency, Nellis Air Force Base, NV (PFC, JR); Military Primary Care Research Network, Bethesda (JTJ); Department of Osteopathic Manipulative Medicine, Ohio University Heritage College of Osteopathic Medicine, Athens, OH (SW).

Funding: none.

Conflict of interest: none declared.

Previous presentations: This work was presented at the 2018 Uniformed Services Academy of Family Physicians Annual Meeting, on March 15th 2018, in Jacksonville, Florida.

Disclaimer: The opinions and assertions contained herein are the private views of the authors and are not to be construed as official or as reflecting the views of US Air Force, the Uniformed Services University of the Health Sciences, or the Department of Defense at large.

Corresponding author: Jeremy T. Jackson, BA, Military Primary Care Research Network, 4301 Jones Bridge Road, Bethesda, MD 20814 (E-mail: jtjackson@hjf.org). sources are depleted and they may be unable to fully engage in clinical encounters, which could in turn create negative feelings about their patients. These negative reactions to patients (depersonalization) may be linked to the experience of emotional exhaustion. ${ }^{1}$ Characterized by emotional exhaustion and depersonalization, burnout is "the final step in a progression of unsuccessful attempts to cope with a variety of negative stress conditions." 2 Physician burnout is associated with lower job performance, decreased quality of patient care, and an increase in medical errors. ${ }^{3,4}$ Among primary care physicians, burnout is associated with increased job stress, greater time pressure during visits, and less control at work. Frequently, quality of care is preserved at the expense of physician wellbeing, ${ }^{5}$ impacting both provider mental health and patient care.

The high rate of physician burnout and the factors contributing to it has become more urgent as the stressors surrounding medical practice multiply. Recent studies have evaluated systemic and 
provider-oriented measures that target possible burnout contributors. ${ }^{6,7}$ Organizational interventions have included duty-hour limitations and facility-specific modifications to improve communication and workflow and promote the development of quality improvement projects. Other interventions target individual behaviors, including mindfulness sessions, stress-management training, small group discussions, healthy exercise habits, work-life balance, and reducing clinical administrative burdens. $^{8-11}$

Another approach to addressing physician burnout is providing continuing medical education opportunities. ${ }^{12}$ One specific type of additional training that has potential to affect physician burnout is acupuncture. Primary care physicians seek to practice acupuncture as a way to provide options for their patients, to focus on patients' whole-person health, and to expand their knowledge and skills. ${ }^{13}$ Acupuncture is a method of treatment using fine needles inserted into predetermined points on the body. ${ }^{14}$ It has successfully treated various clinical conditions including: headache, stress, lower back pain, and other musculoskeletal conditions. ${ }^{15-18}$

Drawing from the premise that burnout in professionals can be reduced by providing avenues for creativity and developing a sense of purpose,${ }^{19}$ we sought to determine if physicians who completed acupuncture training report less emotional exhaustion and depersonalization than those who did not.

\section{Methods}

These cross-sectional data were drawn from an omnibus survey conducted by the Clinical Investigations Committee of the Uniformed Services Academy of Family Physicians. Within the omnibus survey, the acupuncture items were the final set of questions. The sampling frame included family physicians who registered to attend the annual scientific assembly in March 2017. Data were collected anonymously from participants at the meeting. Members not in attendance on the day of presentation were sent an email invitation to participate in the survey. A follow-up email was sent after the initial invitation to encourage nonrespondents to participate. This study was approved by the Uniformed Services University of Health Sciences Institutional Review Board.

\section{Study Variables}

Participants reported demographics, including number of years practice, current percentage of time spent in clinical care, and acupuncture training. A single question assessed level of acupuncture training, asking, "What acupuncture training have you completed?" Respondents could indicate 1 of 4 options: none, battlefield (auricular) acupuncture, advanced battlefield acupuncture, and full $220+$ hour medical acupuncture. This item was collapsed to "no training" versus "auricular and/or medical acupuncture."

The present study uses the 2-item Maslach Burnout Inventory, ${ }^{20}$ which has previously been validated among family physicians. ${ }^{21}$ The single emotional exhaustion item score ranges from 0 to 6 , and the single depersonalization item score ranges from 0 to 6 . To obtain estimates comparable to the full Maslach Burnout Inventory, the emotional exhaustion and depersonalization scores on the single-item measures were multiplied by 9 and 5 , respectively. ${ }^{20}$

\section{Data Analysis}

SPSS $24^{22}$ was used for descriptive and associative statistical tests. Analysis of covariance (ANCOVA) was used to test for an association between completion of acupuncture training and 2 separate dimensions of burnout: emotional exhaustion and depersonalization. Two covariates from previous burnout literature are included: percentage of time in clinical practice ${ }^{23}$ and career stage ${ }^{24}$ measured here by years' practice.

\section{Results}

The overall response rate was $66 \%(325 / 492)$. Of these, 233 respondents (47.4\%) provided complete datasets. Of the 233 respondents, 134 physicians reported completing acupuncture training and 99 reported completing no acupuncture training. Table 1 presents the sample characteristics.

In 2 separate ANCOVAs, controlling for years practice and percentage of time in clinical practice, we tested the effect of acupuncture training on the 2 dimensions of burnout. Emotional exhaustion and acupuncture training were not significantly related. As a covariate, greater percentage of time in clinical practice was associated with greater emotional exhaustion, $P<.05$. The test did not reveal a significant association for years' practice. 
Table 1. Uniformed Services Academy of Family Physicians 2017 Annual Meeting Omnibus Survey Respondents

\begin{tabular}{lc}
\hline Characteristics & $\begin{array}{c}\text { Survey Respondents, } \\
\text { n (\% or SD) }\end{array}$ \\
\hline Practice setting $(\mathrm{n}=216)$ & \\
$\quad$ Clinical & $97(44.9 \%)$ \\
Nonclinical & $105(45.1 \%)$ \\
None of the above & $14(6.5 \%)$ \\
Race $(\mathrm{n}=217)$ & \\
White & $186(79.8 \%)$ \\
African American & $8(3.4 \%)$ \\
Asian American & $10(4.3 \%)$ \\
Native American/Alaskan Native & $2(0.9 \%)$ \\
Mixed or multiple ethnicities & $8(3.4 \%)$ \\
Other & $3(1.3 \%)$ \\
Gender $(\mathrm{n}=219)$ & \\
Male & $143(61.4 \%)$ \\
Female & $76(32.6 \%)$ \\
Mean percentage of time spent in & $52.9(\mathrm{SD}, 32.42)$ \\
$\quad$ clinical care $(\mathrm{n}=210)$ & $11.67(\mathrm{SD}, 8.75)$ \\
Mean years practice $(\mathrm{n}=209)$ & \\
\hline
\end{tabular}

$\mathrm{SD}$, standard deviation.

Acupuncture training was significantly associated with less depersonalization, $F(1,194)=5.82$, $P<.05$. Respondents who had completed acupuncture training reported less depersonalization than respondents who had not completed acupuncture training. In the model, as covariates, higher percentage of clinical time was associated with greater depersonalization, $P<.01$; and more years practice was associated with less depersonalization, $P<.01$. See Table 2 for burnout dimensions by group.

\section{Discussion}

Our results suggest that acupuncture training has the potential to influence burnout among family physicians-particularly by reducing depersonalization. To provide context for the clinical implications, previous research with surgeons demonstrated that every 1-point increase in depersonalization was associated with an $11 \%$ increase in the likelihood of reporting a major medical error. ${ }^{25}$ Therefore, the statistically significant 3-point difference in depersonalization between the 2 groups here suggests a clinically significant impact on patient safety.

Decreased depersonalization may be associated with acupuncture practice as it provides physicians with an approach to develop rapport with patients. In addition, acupuncture is an accessible treatment modality that may provide immediate benefit from which patients experience positive impact rather than the delayed efficacy of traditional treatments. Qualitative research can provide insight into how acupuncture training and practice relates to personalizing the patient. In one study, ${ }^{26}$ patients contrasted their acupuncture experiences with interactions with other physicians/departments about the same condition. In nonacupuncture interactions, patients repeatedly described the physician as not listening or being inflexible, whereas medical acupuncturists were more responsive to patients through listening, answering questions, and not rushing patients. The nature of acupuncture treatments requires physicians to engage with patients more closely, both literately and figuratively. This closeness could have a humanizing effect in the interaction.

In addition, previous research demonstrated the amount of time that an individual pursued an activity in which they were passionately engaged was directly associated to their risk for burnout. ${ }^{27}$ Encouraging scholarly pursuits in new and interesting subjects that inspire passion could further help to inoculate against the effects of burnout. Issues of reimbursement, insufficient time to learn and inflexible medical practices all contribute to this. To truly assess the impact of our study, we need an

Table 2. Burnout Dimension Scores by Group

\begin{tabular}{llcr}
\hline & No Acupuncture Training & Auricular or Medical Acupuncture Training & $P$ Value \\
\hline Emotional exhaustion* $^{*}$ & $26.10(95 \%$ CI, 22.82-29.37) & $23.14(95 \%$ CI, 20.33-25.94) & .188 \\
Depersonalization $^{\dagger}$ & $12.99(95 \%$ CI, 11.12-14.85) & $9.90(95 \%$ CI, 8.29-11.51) & .017 \\
\hline
\end{tabular}

Scores are estimated marginal means as calculated by an analysis of covariance (ANCOVA), controlling for years practice and percentage of time in clinical practice.

*Range, $0-54$, score increases with increased emotional exhaustion.

${ }^{\dagger}$ Range: $0-30$, score increases with increased depersonalization.

CI, confidential interval. 
assessment of physicians' desires to train in acupuncture.

\section{Limitations}

Findings are limited by the cross-sectional survey design and participant sample. Finding time to train in medical acupuncture and incorporate it into practice is a huge challenge. ${ }^{28,29}$ The military setting may have a high uptake of acupuncture due to the structure of the medical system that does not rely on reimbursement for compensation. The sample includes uniformed physicians practicing in military facilities, civilian physicians practicing in military facilities, and retired uniformed physicians practicing in either military or civilian facilities. We did not collect this level of demographic data to be able to address the proportionality of these physician-practice subgroups. The generalizability to other physician groups needs exploration.

More research is needed to understand the reasons physicians choose acupuncture training. It is possible that those seeking acupuncture training have personality styles or coping mechanisms that make them less susceptible to burnout. Additional research should focus on prospectively evaluating burnout measures across acupuncture training, and then attempt to identify which acquired acupuncture skills are the most effective at reducing burnout.

\section{Conclusion}

Acupuncture training may be a viable strategy to prevent or reduce patient depersonalization. This training could enable physicians to build stronger connections to their patients.

The authors acknowledge the leadership of the Clinical Investigations Committee of the Uniformed Services Academy of Family Physicians in its direction of the USAFP omnibus survey. This study was conducted with support from the Military Primary Care Research Network.

To see this article online, please go to: http://jabfm.org/content/ 32/2/259.full.

\section{References}

1. Maslach C, Jackson SE. The measurement of experienced burnout. J Org Behav 1981;2:99-113.

2. Lemkau JP, Purdy RR, Rafferty JP, Rudisill JR. Correlates of burnout among family practice residents. J Med Educ 1988;63:682-691.

3. Krasner MS, Epstein RM, Beckman H, et al. Association of an educational program in mindful communication with burnout, empathy, and attitudes among primary care physicians. JAMA 2009;302: 1284-1293.

4. Welp A, Meier LL, Manser T. Emotional exhaustion and workload predict clinician-rated and objective patient safety. Front Psychol 2014;5:1573.

5. Rabatin J, Williams E, Baier Manwell L, Schwartz MD, Brown RL, Linzer M. Predictors and outcomes of burnout in primary care physicians. J Prim Care Community Health 2016;7:41-3.

6. Goitein L, Shanafelt TD, Wipf JE, Slatore CG, Back AL. The effects of work-hour limitations on resident well-being, patient care, and education in an internal medicine residency program. Arch Intern Med 2005; 165:2601-6.

7. Linzer M, Poplau S, Grossman E, et al. A cluster randomized trial of interventions to improve work conditions and clinician burnout in primary care: Results from the Healthy Work Place (HWP) study. J Gen Intern Med 2015;30:1105-11.

8. Dyrbye LN, Satele D, Shanafelt TD. Healthy exercise habits are associated with lower risk of burnout and higher quality of life among U.S. medical students. Acad Med 2017;92:1006-11.

9. Dyrbye LN, Shanafelt TD. Physician burnout: A potential threat to successful health care reform. JAMA 2011;305:2009-10.

10. West CP, Dyrbye LN, Rabatin JT, et al. Intervention to promote physician well-being, job satisfaction, and professionalism: A randomized clinical trial. JAMA Intern Med 2014;174:527-33.

11. West CP, Dyrbye LN, Erwin PJ, Shanafelt TD. Interventions to prevent and reduce physician burnout: A systematic review and meta-analysis. Lancet 2016;388:2272-81.

12. Kushnir T, Cohen AH, Kitai E. Continuing medical education and primary physicians' job stress, burnout and dissatisfaction. Medical Educ 2000;34: 430-6.

13. Mao JJ, Kapur R. Acupuncture in primary care. Prim Care 2010;37:105-17.

14. Lennard TA. Pain procedures in clinical practice. 3rd ed. Philadelphia, PA: Elsevier/Saunders; 2011.

15. Grant S, Colaiaco B, Motala A, Shanman R, Sorbero M, Hempel S. Acupuncture for the treatment of adults with posttraumatic stress disorder: A systematic review and meta-analysis. J Trauma Dissociation 2018;19:39-58.

16. MacPherson H, Vertosick EA, Foster NE, et al. The persistence of the effects of acupuncture after a course of treatment: A meta-analysis of patients with chronic pain. Pain 2017;158:784-93.

17. Vickers AJ, Cronin AM, Maschino AC, et al. Acupuncture for chronic pain: Individual patient data meta-analysis. Arch Intern Med 2012;172:1444-53.

18. Zarei S, Shayestehfar M, Memari AH, SeifBarghi T, Sobhani V. Acupuncture decreases competitive anxiety prior to a competition in young athletes: A 
randomized controlled trial pilot study. J Complement Integr Med 2017;14.

19. Abaza MM, Nelson KG. Leading by Example: Role Modeling Resilience Helps Our Learners and Ourselves. Acad Med 2018;93:157-8.

20. West CP, Dyrbye LN, Satele DV, Sloan JA, Shanafelt TD. Concurrent validity of single-item measures of emotional exhaustion and depersonalization in burnout assessment. J Gen Intern Med 2012;27:1445-52.

21. Rafferty JP, Lemkau JP, Purdy RR, Rudisill JR. Validity of the Maslach Burnout Inventory for family practice physicians. J Clin Psychol 1986;42:488-92.

22. Bryant A, Blake-Lamb T, Hatoum I, Kotelchuck M. Women's use of health care in the first 2 years postpartum: Occurrence and correlates. Matern Child Health J 2016;20(Suppl 1):81-91.

23. Windover AK, Martinez K, Mercer MB, Neuendorf $\mathrm{K}$, Boissy A, Rothberg MB. Correlates and outcomes of physician burnout within a large academic medical center. JAMA Intern Med 2018;178:856-8.
24. Dyrbye LN, Varkey P, Boone SL, Satele DV, Sloan JA, Shanafelt TD. Physician satisfaction and burnout at different career stages. Mayo Clin Proc 2013;88: 1358-67.

25. Shanafelt TD, Balch CM, Bechamps G, et al. Burnout and medical errors among American surgeons. Ann Surg 2010;251:995-1000.

26. Fisher CL, Ledford CJW, Moss DA, Crawford P. Physician communication to enhance patient acupuncture engagement in family medicine. J Health Comm 2018;1-8.

27. Shanafelt TD, West CP, Sloan JA, et al. Career fit and burnout among academic faculty. Arch Intern Med 2009;169:990-5.

28. Yeh GY, Ryan MA, Phillips RS, Audette JF. Doctor training and practice of acupuncture: results of a survey. J Eval Clin Pract 2008;14:439-45.

29. Ledford CJW, Fisher CL, Moss DA, Crawford PF. Critical factors to practicing medical acupuncture in family medicine. J Am Board Fam Med 2018;31: 236-42. 